\title{
SISTEMAS MULTIMEIOS: CONECTIVIDADE PARA UMA EXPERIÊNCIA DE USO EM AUTOMÓVEIS
}

\section{MULTIMEDIA SYSTEMS: CONNECTIVITY FOR A CAR USE EXPERIENCE}

\author{
Talita Muniz Ribeiro ${ }^{1}$, M.Sc. \\ talitamr@gmail.com e https://orcid.org/0000-0002-5646-1813 \\ Iara Sousa Castro ${ }^{1}$, D.Sc. \\ iara.castro@uemg.br e https://orcid.org/0000-0002-4819-7194 \\ Róber Dias Botelho ${ }^{2}$, D.Sc. \\ rober.botelho@design.ufjf.br e https://orcid.org/0000-0001-6503-4971
}

\author{
${ }^{1,2}$ Centro de Pesquisa em Design e Ergonomia - CPqD, Programa de Pós-Graduação em Design - PPGD, Escola de \\ Design, Universidade do Estado de Minas Gerais, Belo Horizonte, Brasil \\ ${ }^{3}$ NUVEN Design Lab - Núcleo de Virtualidades e Ensaios, Universidade Federal de Juiz de Fora, Juiz de Fora, Brasil
}

Experiência do Usuário, Multimeios, Multimídia Conectividade, Mobilidade

Um novo paradigma manifesta-se em torno dos automóveis, uma mobilidade autônoma, conectada e eficiente. Nesse cenário, objetiva-se com o artigo evidenciar o sistema multimeios como diferencial na experiência do usuário junto à mobilidade digitalizada. Resultado de uma pesquisa de mestrado, a proposta metodológica apresenta natureza básica, caráter exploratório, abordagem qualitativa e realizada através de pesquisa bibliográficas e entrevistas semiestruturadas. As entrevistas focaram em três grupos: profissionais da indústria automotiva, concessionários vendedores e usuários de veículos de passeio. Na análise do conteúdo foram evidenciados pontos presentes nas respostas dos três grupos de entrevistados, a citar: conectividade, sistema multimeios, parcerias com empresas de tecnologia, experiência do usuário automotivo e mobilidade digitalizada. Apesar da oposição de opiniões e pontos de vista entre os entrevistados, foi possível identificar quatro pilares: (a) a conectividade, por meio do sistema multimeios, está cada vez mais em destaque nos automóveis; (b) o sistema multimeios tem se tornado o elemento transacional do carro produto para o carro serviço; (c) é prerrogativa que a indústria automotiva se associe ou incorpore as expertises das empresas de tecnologias e, por fim, (d) a aplicação dos conceitos relacionados à experiência do usuário se mostra indissociável para reduzir as frustrações dos usuários quanto à utilização dos novos automóveis.

\section{User's Experience, Multimedia, Multimedia Connectivity, Mobility}

A new paradigm is manifested around cars, an autonomous connected and efficient mobility. In this scenario, the objective of this article is to show the multimedia system as a differential of user's experience, along with digitized mobility. Result of a master's Program research, this methodological proposal has a basic nature, exploratory character, qualitative approach and it was carried out through bibliographic research and semi-structured interviews. The interviews focused on three Groups: automotive industry professionals; car dealers and passenger vehicles' users. As content analysis, issues existing in responses were evidenced among the three groups of respondents, to be mentioned: connectivity; multimedia; system; partnerships with technology companies, automotive users' experience and digitized mobility. Despite the opposition of opinions or points of view among the interviewees, it was possible to identify four pillars: the connectivity, through multimedia system, is increasingly highlighted for automobiles; the Multimedia system has become an element of transaction from car as product to car service; it is a prerogative for the automotive industry to join or incorporate the expertise of technology companies and, finally, the application of concepts related to user's experience, has become crucial to reduce users' frustration when using new automobiles. 


\section{Introdução}

Diante do desenvolvimento de novas tecnologias nos mais diversos planos e a expansão da internet, as necessidades dos usuários têm sido ampliadas e motivam mudanças, principalmente com relação ao interior do automóvel que mantém basicamente o mesmo arquétipo a mais de um século (MILLER et al., 2016). Esse arquétipo refere-se a bancos, freio de mão e pedais, assim como o painel frontal que engloba o painel de instrumentos e mostradores, os controles relativos a ventilação e ar condicionado, volante e o rádio ou sistema multimeios nos carros mais atuais.

Quando um consumidor está à procura de um carro, este espera encontrar um veículo que possua sistema multimeios que contemple recursos relativos à tecnologia e, caso isso não seja possível, $18 \%$ provavelmente não farão a compra. Aproximadamente $77 \%$ destes consumidores afirmam que utilizam a tecnologia em seus carros através da conectividade. Ao mesmo tempo, $72 \%$ dos consumidores relatam que conectam o smartphone ao carro via bluetooth e que, destes usuários, $79 \%$ o utilizam principalmente para ouvir música. Cerca de $75 \%$ dos usuários entrevistados nesta pesquisa o utilizam para fazer ou receber chamadas telefônicas e 56\% o utilizam para navegação e rastreamento (ABEMD, 2019).

Essas necessidades de uso dos consumidores evidenciam a demanda por um automóvel que tem evoluído para um produto cada vez mais digital, que permite interações através da conectividade e em associação e integração aos aparelhos smartphpnes. Por consequência, isso exige novos conhecimentos, novos concorrentes e parcerias para a indústria automotiva.

O sistema multimeios, considerado no presente artigo, possui amplo significado. Em suas versões mais simplificadas, é conhecido como central multimídia, infotainment ou kit multimídia. Os multimeios estão evoluindo para sistemas mais avançados, complexos de informações, lazer e segurança. Lira (2019) conceitua o sistema multimeios como um componente projetado para concentrar diversas funcionalidades de mídia em um único dispositivo. Dessa forma, os usuários encontram reunidas, em um único sistema, funções ligadas à dirigibilidade, tais como sensor de estacionamento, Global Positioning System (GPS) e câmera de ré, como recursos voltados ao entretenimento, por exemplo: reprodutores de Digital Versatile Disc (DVD); sinal de televisão (TV) digital, músicas e telefonia, por intermédio do sistema bluetooth. Em relação aos equipamentos que são capazes de gerar imagens para fins e entretenimento ainda são proibidos pelo Conselho Nacional de Trânsito ao uso do motorista quando o veículo está em movimento (CONTRAN, 2007).

Os sistemas multimeios consistem em uma união entre hardware e software que, atualmente, são representados pelo bluetooth e a função de emparelhamento do aparelho smartphone. De acordo com Patel e Hodgson (2019), os multimeios se desenvolveram a partir de um simples sistema de áudio para carros, que consistia em: um aparelho de rádio que geralmente continha o acesso a rádios com modulações em amplitude e modulação em frequência (AM/FM); leitor de fita magnética, ou "toca-fitas" e compact disk (CD) player, ambos controlados em um limitado painel com alguns mostradores e controle. Os sistemas mais complexos de hoje são fornecidos por meio de ampla variedade de interfaces, com telas sensíveis ao toque, controles táteis no volante e painel, além dos controles por voz ou por gestos.

Embora a maioria desses recursos seja encontrada individualmente, a integração em um único aparelho, ou sistema, como abordado neste trabalho, possibilita a padronização no funcionamento e mais organização interna do veículo. Além disso, o sistema proporciona um melhor custo-benefício quando comparado à implementação individualizada (LIRA, 2019).

Nos estudos prospectivos, ainda quando da análise da tarefa, as possibilidades de produção de um sistema homem-máquina mais integrado se mostram menos onerosas para a possibilidade de inserção de novas soluções. Além disso, os resultados relacionados à usabilidade se mostram mais efetivos. O autor ainda pontua que, desde a fase inicial de concepção do produto ou sistema, as três qualidades do produto

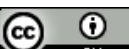


(qualidades técnicas - parte que faz funcionar o produto; qualidade ergonômicas - que garante uma boa interação do produto com o usuário; e qualidade estéticas - que proporciona prazer ao consumidor) devem, sempre que possível, ser solucionadas de forma integrada (IIDA, 2005).

Com isso, a crescente integração da extensas variáveis projetuais que envolvem a concepção de um veículo dentro da nova mobilidade - considerando a diversidade de tecnologias embarcadas, a multiplicidade de uso dos veículos, e a diversidade de usuários envolvidos - tem se mostrado como o caminho para a transformação do simples carro para um "smartcar". Essa é uma característica do designer de sistemas de produtos, uma vez que Löbach (2001, p.194) destaca ao afirmar que "o designer sai então do limitado quadro de formulações isoladas de problemas e concebe sistemas de produtos, abrangendo um conjunto integrado de produtos."

Os processos de digitalização têm permitido uma rápida evolução do sistema multimeios e têm influenciado diretamente na forma como o usuário se "relaciona" com seu veículo. Para Matsubara (2016), assim como foi com os aparelhos celulares, que evoluíram para o atual smartphone, o veículo está próximo de se tornar um "smartcar" em sua essência, trazendo mudanças no comportamento social com relação à utilização dos automóveis.

Dentro desse cenário, o objetivo deste artigo é evidenciar o sistema multimeios como relevante diferencial na experiência do usuário automotivo junto à mobilidade digitalizada.

\section{A experiência pela interação}

A revolução digital alcançou os veículos e, assim como nos demais segmentos do mercado com destaque para os eletrônicos, tem feito profundas alterações nesse produto secular. O processo que teve início com os mostradores para gerenciamento dos veículos, incorporou em seguida o rádio, passando pelos tocadores de músicas - fita magnética e disco compacto digital, e, mais recentemente, pela inclusão dos navegadores por satélites. Cada subsistema apresentava seu módulo distinto e, por vezes, adquiridos separadamente no mercado para serem adaptados ao veículo. Com o tempo, o interior ganhou em integração dos subsistemas e, assim como na transição dos aparelhos celulares para os performáticos smartphones, os veículos se encontram nesse processo transformador.

Nesse processo transformador, por vezes até colocado como disruptivo, a internet foi a variável que mais causou impacto ao interior dos veículos e, por conseguinte, na interação com seus usuários, ou na relação humano-máquina. Chandra, Agani e Prihastomo (2012) confirmam tal condição ao afirmar que os veículos conectados se encontram massivamente equipados com uma diversidade de dispositivos avançados, como: telas de alta definição, sistemas de entretenimento com múltiplas plataformas de comunicação, sistemas de navegação, além de sensores, sistemas de assistência, monitoramento de direção e monitoramento geral do veículo.

A interação humano-máquina (IHM) está diretamente relacionada a um sistema que informa e que permite algum tipo de interação com o usuário (CHAMETON, 2011). Além disso, a interação humano-máquina é abordada pela ergonomia, uma vez que permite avaliar a usabilidade do produto/sistema, além de orientar os projetos com vista a se atingir os objetivos estabelecidos com efetividade, eficiência e satisfação em um contexto específico de uso (ISO 9241-11, 2010). A usabilidade representa a facilidade de uso do produto (IIDA, 2005), sendo que a interação entre a ergonomia, a IHM e o design devem centralizar os objetivos do produto no usuário (MEDEIROS, 2004).

No processo de interação humano-máquina, os usuários aspiram algum benefício quando utilizam os produtos e os serviços. A ideia é realizar alguma atividade, resolver um problema ou experenciar determinada emoção (KALBACH, 2017). Saffer (2010), define, por sua vez, interação como uma transação 
entre duas entidades, troca de informações. A interação em si ocorre entre pessoas, máquinas ou sistemas, em uma variedade de combinações entre eles. Na interação, o designer deve permitir o relacionamento entre pessoas, produtos e serviços, que podem acontecer através de computadores, sistemas automotivos a aplicativos de dispositivos móveis (INTERACTION DESIGN FOUNDATION, 2019).

No binômio design/experiência, ou design da experiência, o fulcro é garantir a qualidade na entrega da experiência em um produto ou serviço (UNGER e CHANDLER, 2009). Como produto, e mais recentemente como vetor de serviços, o automóvel permite-nos definir como indivíduos através dos sentimentos de identidade e localização (SUDJIC, 2010).

\section{Experiência o usuário automotivo}

Quando uma pessoa dirige seu carro, ela e o veículo se tornam um sistema integrado em movimento, como em um relacionamento simbiótico. Este existe devido aos três níveis de processamento do cérebro humano: o visceral (processamento automático e subconsciente); o comportamental (habilidades aprendidas, na sua maior parte subconscientes, nosso comportamento); e o nível reflexivo (parte consciente, autoimagem da pessoa). "O sistema carro motorista é inteligente, emocional e consciente" (NORMAN, p.46, 2010).

Quando os automóveis surgiram, ainda no século XVIII, eles proporcionavam aos condutores os três níveis de processamento ao mesmo tempo. Devido ao aumento da tecnologia, mais elementos viscerais foram acrescentados aos veículos, tornando-os cada mais emocionais. O automóvel lida com funções que vão além do motor, combustível e mudanças de marcha, ele assume, cada vez mais, o nível comportamental da direção. O automóvel atua ainda, como visceral e o motorista no papel reflexivo, com ambos ativos ao nível comportamental. Quando os carros autônomos estiverem disponíveis para a população em geral, não haverá motorista e todos serão passageiros. Por conseguinte, o sistema atual, carro mais motorista será extinto, evidenciando veículos e pessoas separadamente. O automóvel se tornará mais visceral, comportamental e reflexivo ao mesmo tempo, tornando-se uma máquina autônoma e inteligente (NORMAN, 2010).

Com esse salto tecnológico, está surgindo uma nova era da experiência em veículos, em que os sistemas audiovisuais, através do sistema multimeios, têm ganhado cada vez mais destaque no interior dos novos modelos. Ressalta-se que as tecnologias automotivas já caminharam para além do rádio, bluetooth e GPS. Já é possível parear aparelhos de telefone e acessar algumas funcionalidades, como a distribuição de dados, ou o streaming de música, aplicativos e até mesmo acessar informações sobre o funcionamento do veículo (PATEL; HODGSON, 2019).

Algumas montadoras se conectam diretamente com os seus clientes através dos multimeios de seus carros, pois, a tecnologia embarcada nestes dispositivos, permite antecipar suas necessidades. $\mathrm{O}$ veículo pode comunicar problemas diretamente aos revendedores, que por sua vez, podem convidar os clientes para virem até a concessionária para fazer uma revisão, por exemplo. Isto já é feito pela BMW na Alemanha. Segundo Michelli (2017), no caso de correções simples, brevemente, todas as montadoras poderão fazer as atualizações remotamente pelo sistema operacional do veículo, do mesmo modo que o indivíduo recebe as atualizações recentes em seu smartphone. Dados de diagnóstico do veículo irão direto para a concessionária, alertando-a para a necessidade do serviço previamente agendado

A tendência de interfaces automotivas é o primeiro passo para a revolução que se aproxima (PATEL; HODGSON, 2019). Telas cada vez maiores já podem ser encontradas no interior de veículos. A tecnologia será mais acessível e disponibilizada para a ampla categoria de veículos, visando atender diferentes públicos e demandas. Essa tendência mostra que as pessoas têm procurado experiências mais conectadas aos demais sistemas digitais que já integram o cotidiano. 


\section{Sistema Multimeios}

Atualmente, o componente sistema multimeios se apresenta no interior dos veículos, geralmente posicionado ao centro do painel principal, através de uma interface em tela tátil. Conforme o periódico Autoesporte (2018), para se obter um bom sistema multimeios, é necessário verificar a ficha técnica do componente, seja ele um equipamento original de fábrica ou comprado a parte. Dessa forma, é necessário verificar se o processador do sistema é rápido, se a interface possui uma resolução de tela de qualidade, se há espaço de memória, capacidade de carregamento por entrada USB (Universal Serial Bus, ou porta serial universal, em tradução livre) e, principalmente, se existe a possibilidade de integrar ou parear com smartphones. Existem Sistemas Operacionais Automotivos de Conectividade (SOACs), como por exemplo Apple CarPlay, Android Auto e MyLink, que são interfaces que permitem estabelecer a "pareabilidade" entre os smartphones e os sistemas multimeios, assim como, a interação dos mesmos com os usuários. Acrescenta-se que para se garantir uma boa funcionalidade em um sistema multimeios, é necessário avaliar quesitos como legibilidade das informações disponibilizadas, uma vez que tais características interferem diretamente no entendimento dos usuários sobre as informações apresentadas nas telas. Além disso, a visibilidade pode ser afetada devido à ocorrência de ofuscamentos e reflexos (BHISE, 2012).

Os sistemas multimeios deixaram de ser exclusivos para segmentos de automóveis de luxo. Eles estão presentes na maior parte dos modelos, sendo solicitado por $80 \%$ dos clientes na hora da compra de veículos novos e por $60 \%$ no mercado de usados, onde o fato do veículo possuir os sistemas multimeios originais de fábrica, aumentam as possibilidades de revenda (FONTANA, 2016).

Um problema a se destacar, sobre o atual sistema multimeios, refere-se ao seu uso pouco intuitivo. O usuário não tem interesse em ler manuais e instruções de funcionamento para melhor interagir com o componente. Ele busca aprender apenas utilizando o componente, o que acaba restringido seu uso para funções básicas que estão mais aparentes na interface do sistema multimeios (SILVA, 2016).

A evolução digital tornou o conceito de bem-estar, aliado às necessidades e expectativas das pessoas, mais desafiador para os projetistas veiculares. Os usuários desejam acessar as mesmas funções e conteúdo que acessam em seus computadores e, especialmente, nos smartphones, de forma rápida e acessível. Isso significa que as necessidades dos usuários e suas respectivas percepções de valores foram afetados pela digitalização do automóvel. O conceito de experiência e interação evoluiu para uma característica com valor mais representativo que o próprio conteúdo original do sistema (SILVA, 2016).

Portanto, verifica-se que a experiência deve ser reprojetada em novos sistemas multimeios de veículos, de forma que estes devam apresentar informações de fácil uso, lembretes pontuais e recursos que favoreçam a interação com o sistema operacional e, por conseguinte, a resolução de tarefas.

\section{Procedimentos metodológicos}

Esta pesquisa foi baseada em procedimentos metodológicos como revisão bibliográfica, análise documental, coleta de dados por meio de entrevistas semiestruturadas e análise dos dados coletados.

A revisão bibliográfica foi direcionada para a compreensão da experiência do usuário com foco na utilização dos sistemas multimeios veiculares; da evolução histórica da arquitetura e da influência dos sistemas multimeios; e da evolução dos multimeios que perpassa para um componente indispensável à mobilidade futura. A análise documental voltou-se para a compreensão das normas e procedimentos de uso dos sistemas multimeios.

A coleta de dados por meio de entrevistas semiestruturadas foram realizadas com três grupos de entrevistados com o seguinte perfil: (a) profissionais da indústria automotiva, com pelo menos dois anos de 
atuação em equipes encarregadas pela projetação da experiência, especialmente, na utilização de sistemas multimeios; (b) vendedores concessionários, ativos e com pelo menos dois anos de experiência no cargo e que possuíssem informações sobre a decisão de compra dos clientes em relação aos sistemas multimeios; (c) usuários de veículos de passeio com idade entre 21 e 60 anos, ativos na dirigibilidade de veículos e conduzissem veículos no mínimo três vezes por semana, assim como possuíssem veículos com painel multimídia.

Com cada grupo, as questões foram formuladas a partir de um roteiro pré-definido, porém não rígido. $\mathrm{O}$ intuito das entrevistas realizadas com o grupo de profissionais da industrial automotiva foi entender a contrapartida da indústria e do mercado com relação à experiência ofertada ao usuário. Em relação ao grupo de vendedores concessionários, as questões foram direcionadas para explorar a importância da conectividade e do sistema multimeios nas vendas de veículos, visando ratificar os conceitos apresentados sobre experiência do usuário conectividade e mobilidade, apresentados nas referências bibliográficas e entender sua influência e importância nos projetos automotivos. Por fim, ao considerar que as vozes do usuário são a evidência mais convincente que se pode fornecer sobre o que está funcionando em um determinado produto ou serviço (NUNALLY; FARKAS, 2017). Assim, para o grupo de usuários elaborou-se perguntas direcionadas para verificar a importância da conectividade e do sistema multimeios no uso do veículo, como também, quais são os anseios destes indivíduos, para este componente no futuro, visando entender quais são os aspectos que interferem na experiência do usuário.

As entrevistas foram realizadas por telefone ou por meio de plataforma que propiciavam a comunicação entre os interlocutores à distância motivada pelo contexto da pandemia da COVID-19. Com a permissão dos participantes, as entrevistas foram gravadas e, posteriormente, transcritas para ser feita uma análise mais detalhada da coleta de dados.

Para a coleta de dados, foram abordados cinco participantes de cada grupo de entrevistados, totalizando 15 participantes. Conforme Agner (2018) e Lowdermilk (2013), com essa amostragem é possível identificar cerca de $80 \%$ dos problemas críticos de um produto. No caso específico desta pesquisa, notou-se que as informações começaram a se repetir, alcançando a saturação dos dados. Por meio desta saturação, foram identificadas informações que foram compiladas em cinco categorias principais que serão explicadas nos resultados: (a) conectividade, (b) sistema multimeios, (c) parcerias com empresas de tecnologia, (d) experiência do usuário automotivo e (e) mobilidade digitalizada.

\section{Resultados}

Os resultados evidenciaram pontos de congruências e divergência entre os três grupos de entrevistados, assim como impressões a respeito da importância da conectividade e de alguns pontos subjetivos inerentes à interação do usuário com o sistema multimeios, das parcerias com empresas de tecnologia, da experiência do usuário e da mobilidade digitalizada, que foram evidenciadas pela coleta de dados.

\subsection{Conectividade}

A valorização ascendente do componente sistema multimeios, como um elemento de conectividade dentro do veículo. Esse dado foi identificado para quatorze dos quinze entrevistados, o que aponta ser um componente automotivo imprescindível aos três grupos de participantes.

Complementando essa constatação, um entrevistado do Grupo Concessionário afirmou que as pessoas estão mais conectadas e necessitam acessar o telefone dentro do veículo para visualizar as mensagens, e-mail, ou tratar assuntos em tempo real. Neste contexto, o sistema multimeios é o componente que representa a conectividade em si, já que permite a integração e o acesso a alguns dos recursos presentes no smartphone no próprio veículo. 
Salienta-se que para os entrevistados do Grupo de Usuários, o automóvel ainda representa um símbolo de status e a conectividade deve ser um elemento visível no interior do veículo. Para isso, este componente deve revelar-se por meio de um substrato físico, palpável e, no caso dos sistemas multimeios, por meio de uma tela grande e bem exposta, pois ela é o principal ponto de interface entre o usuário e o sistema multimeios.

Sendo assim, é possível constatar que o usuário hoje ainda está focado no componente físico em si e entende a conectividade como um hardware. O usuário ainda necessita da sensação tátil, de visualizar uma tela com relevantes proporções.

Para os entrevistados do Grupo Profissionais, a digitalização do automóvel está em nítida expansão no mundo e que em menos de cinco anos este cenário será diferente também no Brasil. A exigência do consumidor deixará de ser a questão estética, visual do componente e se tornará um sistema multimeios com mais recursos tecnológicos e, especialmente, que seja de uso mais intuitivo.

Outro ponto discutido dentro da temática da conectividade se trata do entendimento dos entrevistados sobre o que vem a ser um carro conectado. Todos os cinco entrevistados do Grupo de Usuários afirmaram acreditar que isso significa que os veículos terão acesso direto à internet, serão interativos, se comunicarão entre si e permitirão o envio e recebimento de todo tipo de dados, desde informações sobre o veículo, funcionamento, dirigibilidade e, também, as informações pessoais e dados de uso.

Um entrevistado do Grupo de Usuários relatou que, para ele, um carro conectado é um carro que conversa com ele, que informa sobre manutenção, segurança e problemas mecânicos que possam vir a ocorrer, ou seja, que auxilie na mobilidade e dirigibilidade do veículo. Outro entrevistado do Grupo de Usuários, acredita que o carro estar conectado pode ser perigoso, pois, para ele, compartilhar dados pessoais significa ser monitorado, vigiado ou até mesmo induzido ao consumo impulsivo.

Os demais entrevistados do Grupo de Usuários relataram ter receios em disponibilizar dados pessoais para o veículo. Demonstraram sentimentos ambíguos, pois, ao mesmo tempo em que estão abertos e que anseiam pela entrada de novas tecnologias, apresentaram dúvidas de como será efetuada essa disponibilização de dados. Estes questionaram se os dados poderão ser utilizados para controlar o veículo sem sua permissão, ou para persuadi-los a fazer algo, como consumir algum produto. Essa tensão acerca do compartilhamento de dados ocorre devido ao pouco conhecimento dos usuários sobre as possibilidades de um sistema multimeios. A preocupação acerca do uso de dados já é amplamente discutida por autoridades governamentais (LGPD, 2018; EDPB, 2020;) e é legítima.

Sendo assim, foi possível verificar que existe uma necessidade evidente de que a conectividade extrapole as barreiras dos dispositivos smartphones, tablets e computadores portáteis existentes hoje e englobe, também, o carro. O componente que permitirá tal integração será o sistema multimeios.

\subsection{Sistemas multimeios}

O componente sistema multimeios, segundo o Grupo de Profissionais, é um hardware de interação humanomáquina. Este componente faz parte do contexto de interação do veículo entre a tecnologia e as pessoas. Os multimeios atuais fornecem tanto informações técnicas sobre o veículo, relacionadas à dirigibilidade $\mathrm{e}$ segurança, tanto como informações totalmente dissociadas ao ato de dirigir.

As funções relacionadas mais diretamente ao usuário (lazer e trabalho, por exemplo), definem o significado do que é o componente sistema multimeios para os entrevistados dos Grupos de Usuários e de Concessionários em sua totalidade. O sistema fornece acesso a músicas, parte das funções do telefone e navegação, que são as funções básicas acessadas neste sistema pelos usuários. 
Colaborando com o exposto anteriormente, para um entrevistado do Grupo Profissional, o sistema multimeios é um dos componentes mais complexos dentro do veículo devido ao projeto dos hardwares envolvidos. O mesmo deve funcionar com uma velocidade específica, sendo um sistema que interage direta e constantemente com o usuário que, por sua vez, espera relevante performance do equipamento.

Já para os entrevistados dos Grupos de Concessionários e de Usuários, o componente multimeios significa, também, a possibilidade de interação com o smartphone. Dessa forma, a principal demanda atual, apontada inequivocamente pelos três Grupos, refere-se ao espelhamento do smartphone. Quatro dos cinco entrevistados do Grupo de Usuários disseram que gostariam de ter as funções do seu smartphone, principalmente as relativas à navegação, visualizadas ou mais acessíveis na tela do sistema multimeios.

Quando questionados sobre o que eles gostariam que tivesse em um sistema multimeios, três dos cinco entrevistados do Grupo de Usuários relataram que deveria haver uma maior sincronização com o smartphone e com algumas de suas informações, como lembretes de agenda e acesso às informações em plataformas de armazenamento online.

Quatro dos cinco entrevistados do Grupo de Usuários disseram que não voltariam a adquirir um veículo sem o sistema multimeios, mesmo aqueles que o utilizam com pouca frequência. Um entrevistado do Grupo de Usuários declarou que o sistema multimeios é uma evolução em relação às antigas "disqueteiras" e "tocafitas", que, muitas vezes, eram de difícil acesso, pois, eram localizados no porta-malas de veículos. Para esse usuário, não ter um sistema multimeios é algo significativamente antigo, sendo razão para não voltar a possuir um veículo sem o componente. Outro entrevistado do Grupo de Usuários, utilizou a palavra "jamais" sobre possuir um veículo sem o sistema multimeios. Isso significa que para $80 \%$ dos entrevistados do Grupo de Usuários e a totalidade dos entrevistados do Grupo de Concessionários, o sistema multimeios tornou-se um componente essencial no interior do automóvel.

\subsection{Parcerias com empresas de tecnologia}

As entrevistas permitiram expor que as parcerias entre os fabricantes veiculares com empresas de tecnologia poderão ampliar as possibilidades do espelhamento/pareamento do smartphone. Os cinco entrevistados do Grupo Concessionários citaram que o pareamento entre o smartphone e o multimídia por meio de interfaces, como os Sistemas Operacionais Automotivos de Conectividade (SOACs), é um diferencial em seus produtos e um marco para o crescimento das vendas dos sistemas multimeios. A qualidade dessas interfaces, SOACs, influencia diretamente a interação entre os usuários e o multimeios.

Para o Grupo de Concessionários, a partir do momento em que os carros ofereceram a interação dos usuários com o multimídia por meio dos SOACs, o consumidor passou a ter mais autonomia com relação ao uso do telefone e acesso a uma navegação atualizada em tempo real, podendo utilizar aplicativos do seu smartphone. Assim os aplicativos do telefone passaram a ser visualizados diretamente na tela do sistema multimeios.

Ainda com relação à parceria dos fabricantes automotivos com empresas de tecnologia, perguntou-se para os entrevistados dos Grupos de Usuários e Profissionais como eles percebiam a entrada desses novos fornecedores na indústria automotiva. O propósito foi delinear opiniões e pontos de vista dos entrevistados sobre os possíveis benefícios e malefícios que essas parcerias poderão oferecer para os sistemas multimeios de veículos.

Quatro dos cinco entrevistados do Grupo de Usuários afirmaram que será benéfica a parceria com empresas de tecnologia, apesar de possuírem certa desconfiança quanto a disponibilização de dados. Tal receio é consequência das práticas ilícitas de compartilhamento de dados pessoais e de utilização dos equipamentos realizadas atualmente por empresas de tecnologia, com as quais seriam feitas essas parcerias, pois adquire-se 
o veículo de um dado fabricante automotivo e os dados coletados permearão outras empresas envolvidas. Percebe-se que mesmo existindo a LGPD, o receio do usuário ainda é evidente.

De outro modo, para todos os entrevistados do Grupo de Profissionais, essas parcerias são uma tendência de mercado e serão positivas, justamente por fornecer dados de usuários, permitindo, assim, que possam ser desenvolvidos sistemas e serviços mais personalizados e individualizados para o usuário. Os mesmos entrevistados afirmam, também, que as empresas de tecnologia possuem um aporte mais extenso de conhecimento acerca de produtos e serviços digitais, além de trabalharem com processos novos e ágeis, bem diferente dos processos centenários praticados na indústria automotiva.

Dessa forma, segundo os entrevistados do Grupo de Profissionais, as empresas de tecnologia não serão concorrentes diretos da indústria automotiva, mas parceiras ideais para modernizar os processos e tornar o carro um produto digital e conectado. Isso ocorre devido ao fato de as pessoas estarem cada vez mais conectadas ao smartphone e desejarem que as soluções de conectividade encontradas neste aparelho estejam disponibilizadas também no veículo. Esse aspecto é uma forma de estender a condição pessoal dos usuários dos smartphones quando da utilização direta dos veículos.

\subsection{Experiência do usuário automotivo}

O carro está se tornando cada vez mais multifuncional, transformando-se em uma plataforma que possibilita a incorporação de recursos e conteúdos diversos através das tecnologias relacionadas à conectividade. Segundo um entrevistado do Grupo de Profissionais, o sistema multimeios está se tornando um componente sistematizador, que vai se associar a outros componentes, como o painel de instrumentos, e se tornar um elemento central de dirigibilidade e entretenimento.

As entrevistas e o estudo bibliográfico mostram que haverá uma relação próxima, emocional e conectada como a que existe hoje entre o usuário e o smartphone - uma relação simbiótica do carro com usuário, conforme apontado por Norman (2010).

Os entrevistados do Grupo de Usuários esperam que os novos projetos de sistemas multimeios, dos próximos carros que adquirirão, estejam mais integrados e que os problemas atuais, tais como: complexidade de uso; falta de espelhamento e pareabilidade com smartphone; entre outros, sejam sanados.

Segundo um entrevistado do Grupo de Profissionais, o Brasil, diferente de outros mercados, ainda está no início da consolidação do sistema multimeios, pois os sistemas multimeios oferecidas no país ainda são limitados. De acordo com esses entrevistados, este componente, no mercado brasileiro, ainda está defasado, oferecendo o mínimo de recursos. Isto significa que o consumidor brasileiro exige pouco da performance desse componente atualmente, o que ocorre devido ao fato de o perfil do usuário brasileiro ser de não explorar todas as possibilidades do sistema multimeios que adquiriu, diferente do usuário norte americano e europeu, por exemplo. Contudo, também atribui-se uma explicação, ao fato da consolidação dos sistemas multimeios ainda se encontrar no início, voltada para o custo para adquiri-los, uma vez que são equipamentos mais caros no Brasil do que em muitos outros países devido aos impostos atribuídos ao produto.

Divergindo da afirmação anterior, outro entrevistado do Grupo de Profissionais disse que cada vez mais essa diferença em relação aos outros mercados diminuirá, principalmente porque os desenvolvimentos de novos produtos têm sido globalizados. As dificuldades, segundo este entrevistado, se relacionam mais diretamente com: os custos projetuais, a infraestrutura local, as questões como geolocalização e GPS, a infraestrutura de telecomunicações, que em outros países, como Estados Unidos e Europa, são mais desenvolvidos. Segundo o entrevistado, este cenário está mudando, pois, o mercado brasileiro tem amadurecido rápido e o cliente, consequentemente, demandará conectividade no veículo com mais rapidez. Dessa forma, em breve as pessoas deixarão de comprar carros que não atendam às suas expectativas relativas conectividade. 
Durante as entrevistas junto ao Grupo de Profissionais, foi perceptível a tendência para uma mudança do foco projetual, que antes era centrado apenas no motorista e que, a partir do momento em que o acesso a carros autônomos for difundido e democratizado, boa parte dos usuários se tornarão passageiros a depender do nível de automatização do veículo. Portanto, a conectividade passa a ser pensada para todos que utilizam o veículo.

Para os mesmos entrevistados, os carros autônomos são uma tendência, mas esses veículos ainda coexistirão com os carros de condução convencional. Confirmando tal afirmação, ao serem questionados se utilizariam carros de condução autônoma, apenas dois dos cinco entrevistados do Grupo de Usuários afirmaram que, com certeza utilizariam esses carros, embora a aceitabilidade dos carros autônomos ainda esteja em um processo de transição. No Brasil, esse processo ainda parece ser mais distante, pois ainda não existem empresas de grande porte que estejam desenvolvendo esses veículos no país.

\subsection{Mobilidade digitalizada}

Para quatro dos cinco entrevistados do Grupo de Usuários, nova mobilidade significa a entrada de novas tecnologias que possibilitam a melhoria da dirigibilidade e do conforto dentro do carro. Um destes entrevistados relatou que, para ele, a mobilidade vai além da tecnologia e se refere também ao desenvolvimento de novos modais de transporte e serviço.

Outro entrevistado do Grupo de Usuários descreveu a mobilidade digitalizada como uma forma de redescobrir novas e velhas maneiras de se locomover, de ter mais acessibilidade, de gerar menos trânsito e, também, a possibilidade do uso de outros meios de transporte, por exemplo através de aplicativos de mobilidade.

Os entrevistados do Grupo de Profissionais fizeram uma análise mais profunda sobre a mobilidade e relatam perspectivas possíveis para a indústria e para o mercado. Estes entrevistados demonstram ciência das mudanças que estão por vir e do futuro que cerca o conceito de mobilidade. Isto se deve à experiência profissional, fato que exige pesquisas intensas as tendências do mercado para o setor.

Para complementar o conceito de mobilidade, um questionamento sobre serviços de mobilidade foi feito a todos entrevistados dos três grupos. Para os entrevistados do Grupo de Usuários, foi questionado se os mesmos utilizariam algum tipo de serviço de mobilidade de maneira geral (por exemplo, aplicativos de transporte privado urbano, de compartilhamento de veículos, de compartilhamento de viagens...) e o que eles pensavam a respeito. Quatro dos cinco entrevistados não só já utilizaram, como também estavam dispostos a utilizar ainda mais. No caso dos entrevistados do Grupo de Concessionários, o questionamento referente aos serviços de mobilidade voltou-se a verificar se o aumento da procura dos consumidores por um veículo para trabalhar, com estes serviços de mobilidade, e se estes consumidores buscam por carros com os sistemas multimeios. Todos os entrevistados foram unânimes em dizer que estes consumidores priorizam o baixo custo do veículo e não um veículo com sistema multimeios. Para eles, o ideal é adquirir um veículo que atenda aos requisitos mínimos exigidos pelos aplicativos. A disponibilidade dos sistemas multimeios é considerada uma vantagem, mas, não uma exigência básica no ato da aquisição do produto.

Para facilitar a comparação entre as percepções dos Grupos de entrevistados sobre os cinco pontos identificados, tem-se o Quadro 1. 


\begin{tabular}{|c|c|c|c|c|c|}
\hline $\begin{array}{c}\text { Grupo de } \\
\text { entrevistados }\end{array}$ & $\begin{array}{l}\text { Relevância } \\
\text { quanto à } \\
\text { conectividade }\end{array}$ & $\begin{array}{l}\text { Relevância } \\
\text { quanto ao } \\
\text { sistema } \\
\text { multimeios }\end{array}$ & $\begin{array}{c}\text { Relevância quanto } \\
\text { às parcerias com } \\
\text { empresas de } \\
\text { tecnologia }\end{array}$ & $\begin{array}{c}\text { Relevância quanto à } \\
\text { experiência do } \\
\text { usuário automotivo }\end{array}$ & $\begin{array}{l}\text { Relevância quanto } \\
\text { à mobilidade } \\
\text { digitalizada }\end{array}$ \\
\hline $\begin{array}{c}\text { Grupo de } \\
\text { Concessionários }\end{array}$ & $\begin{array}{l}\text { Espelhamento } \\
\text { do smartphone }\end{array}$ & $\begin{array}{l}\text { Hardware de } \\
\text { recursos de } \\
\text { conectividade }\end{array}$ & $\begin{array}{l}\text { Maior oferta de } \\
\text { sistemas de } \\
\text { conectividade }\end{array}$ & $\begin{array}{l}\text { Carro completo: } \\
\text { econômico, confortável } \\
\text { e com multimeios, } \\
\text { espelhamento }\end{array}$ & $\begin{array}{l}\text { Internet dentro do } \\
\text { carro }\end{array}$ \\
\hline $\begin{array}{l}\text { Grupos de } \\
\text { Profissionais }\end{array}$ & $\begin{array}{l}\text { Soluções de } \\
\text { interação para } \\
\text { dentro do } \\
\text { carro }\end{array}$ & $\begin{array}{c}\text { Plataforma em } \\
\text { expansão de } \\
\text { sistemas, serviços } \\
\text { e conteúdo }\end{array}$ & $\begin{array}{c}\text { Tendência benéfica } \\
\text { para indústria } \\
\text { automotiva, maior } \\
\text { acesso a dados de } \\
\text { usuários e produtos } \\
\text { digitais }\end{array}$ & $\begin{array}{l}\text { Definida através do } \\
\text { desenvolvimento } \\
\text { tecnológico, aspectos } \\
\text { comportamentais e } \\
\text { necessidades }\end{array}$ & $\begin{array}{c}\text { Acessibilidade, } \\
\text { serviço, } \\
\text { multimodais, facilitar } \\
\text { jornadas com a } \\
\text { tecnologia }\end{array}$ \\
\hline $\begin{array}{l}\text { Grupo de } \\
\text { Usuários }\end{array}$ & $\begin{array}{c}\text { Status, } \\
\text { hardware, } \\
\text { espelhamento } \\
\text { do smartphone }\end{array}$ & $\begin{array}{l}\text { GPS, bluetooth, } \\
\text { telefonia e } \\
\text { áudio/música }\end{array}$ & $\begin{array}{c}\text { Receio quanto ao } \\
\text { compartilhamento de } \\
\text { dados }\end{array}$ & $\begin{array}{c}\text { Soluções para os } \\
\text { problemas atuais dos } \\
\text { multimeios. } \\
\text { Comodidade, } \\
\text { acessibilidade e } \\
\text { conectividade } \\
\end{array}$ & $\begin{array}{l}\text { Mais tecnologia } \\
\text { para dentro do caro } \\
\text { e nos transportes } \\
\text { em geral }\end{array}$ \\
\hline
\end{tabular}

Quadro 1: Resumo geral sobre a relevância quanto as parcerias com empresas de tecnologia. Fonte: Ribeiro (2020, p.79).

\section{Discussão}

O confronto entre as entrevistas realizadas com os três Grupos entrevistados (Profissionais da indústria automotiva, Concessionários e Usuários) permitiu obter uma visão panorâmica do estudo, verificando quais fatos indicam a relevância dos sistemas multimeios na experiência do usuário de automóveis.

Foram evidenciados os pontos favoráveis e os pontos desfavoráveis mencionados, com relação às temáticas principais apontadas nos resultados da pesquisa:

a) Conectividade:

O primeiro tema discutido, a conectividade, está associada, para o Grupo de Usuários, ao acesso à internet. Já para os entrevistados no Grupo de Concessionários, se relaciona à pareabilidade com o smartphone, enquanto para o Grupo de Profissionais, a conectividade é o fator viabilizador de mudanças no produto carro. Todos estes pontos foram evidenciados como favoráveis em relação a conectividade.

Dentre os pontos desfavoráveis identificados, verifica-se que atualmente a conectividade ainda não gera tanto valor para o cliente brasileiro, o que se deve à falta de entendimento sobre seu funcionamento, que se limita às funções básicas e, possivelmente, ao custo e à usabilidade desses sistemas. O motivo é que, conforme entrevistados do Grupo de Profissionais, para qualquer usuário, ter muitas funcionalidades não significa que um produto traga uma boa experiência e uma boa interação. Esse foi um ponto levantado no Grupo de Usuários, o que pode explicar o fato do baixo investimento dos fabricantes de veículos.

Tal situação corrobora com a alegação exposta por Kamei em entrevista (apud COZER, 2020), é necessário que o usuário seja educado quanto ao uso de tecnologias, mais exposto e estimulado as mesmas para que assim se possam permitir veículos conectados.

Dessa forma, deve-se pensar na conectividade como algo a longo prazo, no qual as montadoras devem analisar o custo da conectividade como um investimento. Esse aporte permitirá que haja tempo hábil para a preparação do usuário de forma que este entenda e associe valor à tecnologia embarcada nos sistemas multimeios. 
b) Sistemas Multimeios:

Quanto ao sistema multimeios, as entrevistas expuseram que os participantes do Grupo de Usuários em geral estão se tornando mais dependentes desse componente, assim como têm se tornado dos smartphone, apesar dos sistemas multimeios ainda serem um componente pouco explorado por este Grupo, o que é visto como ponto desfavorável pelo Grupo de Profissionais.

Ainda sobre o sistema multimeios, conforme destacado pela ABEMD (2019), o carro que não oferecer o componente não vende. Isso pode ser confirmado pelos entrevistados do Grupo de Concessionários ao classificarem a presença deste sistema como um ponto favorável. Tal aspecto significa que apenas a presença do hardware no veículo já se constitui um fato decisivo na definição de compra. Esse comportamento do Grupo de Usuários pode ser correlacionado ao já apresentado, quando estes ainda enxergam nos multimeios um símbolo de modernidade e status.

Além disso, identificou-se que o usuário brasileiro, de acordo com os entrevistados do Grupo de Usuários, apenas verifica com o vendedor, no momento de retirar do veículo da concessionária, quais são as funções básicas do sistema multimeios. É um ponto desfavorável para o Grupo de Usuários ter que fazer leitura do manual de instruções do componente para conhecer e aprofundar sobre as funcionalidades. $\mathrm{O}$ usuário não tem interesse em ler tantas informações técnicas (Silva, 2016), pois o sistema por si só deveria ser fácil o suficiente para que o usuário navegue por todas as suas partes e descubra as suas potencialidades. O Grupo de Profissionais tem essa percepção sobre o sistema.

Paradoxalmente, o usuário em geral não apresenta interesse em ler as instruções de uso do sistema, mesmo considerado como ponto desfavorável a complexidade de uso. Dessa forma, o usuário normalmente utiliza as mesmas funcionalidades básicas ao longo de todo o período de posse do veículo. Verifica-se, com isso, que o uso do componente sistema multimeios deverá se mostrar mais intuitivo quando abordado junto ao Grupo de Usuários.

Logo, pode-se aferir que o sistema multimeios é um diferencial para os entrevistados do Grupo de Concessionários, pois a presença de uma tela digital é um ponto positivo no ato da venda do veículo. Um importante indicativo de sucesso comercial.

Enquanto para o Grupo de Usuários a presença do sistema multimeios se mostra favorável, devido à possibilidade de acesso à internet e à representação de modernidade e status, para o Grupo de Profissionais, o componente vai além, tornando-se um pórtico de conectividade para a digitalização do automóvel.

c) Parcerias com empresas de tecnologia

No que se refere às parcerias com empresas de tecnologia, estas se mostraram fundamentais para o Grupo de Profissionais, principalmente para que se possa mapear e acessar dados de experiência. Como apontado por Lowdermilk (2013), as métricas são geradas a partir dos dados dos usuários, obtidos através das ferramentas de experiência do usuário.

Conforme exposto nos resultados, o Grupo de Profissionais indica que somente através das parcerias entre os fabricantes de automóveis e os fabricantes de tecnologia será possível ter acesso a esses tipos de dados mencionados, já que as empresas de tecnologia possuem as ferramentas e a competência comercial necessárias para gerar dados sólidos. Essa aproximação industrial tornará os processos mais ágeis e automatizados, além de oferecerem as ferramentas necessárias para construir testes de usabilidade no desenvolvimento de produtos digitais.

Ter acesso a dados é fundamental para o desenvolvimento de novos sistemas multimeios, conforme apontado pelo Grupo de Profissionais. Eles afirmam que em breve os multimeios estarão cada vez mais integrados a 
outros produtos digitais, como o smartphone, que estão incorporados à vida do usuário. Sendo assim, esta fusão entre smartphone e multimeios torna o carro um smartcar, conforme denominado por Matsubara (2016), sendo este um ponto favorável tanto para o Grupo de Profissionais quanto para o Grupo de Usuários.

\section{d) Experiência do usuário automotivo}

No que tange a experiência do usuário automotivo, para o Grupo de Concessionários, o ponto favorável diz respeito a se oferecer um carro completo que atenda às expectativas do cliente. Já para o Grupo de Usuários, a vantagem é ter mais tecnologia a bordo, principalmente quanto ao acesso à internet, tal qual Chandra, Agani e Prihastomo (2012) apontam.

Para os entrevistados do Grupo de Profissionais, a falta de conhecimento tecnológico, por parte do usuário, bem como o mercado limitado pelo baixo custo e legislações burocráticas, afetam diretamente o projeto de uma boa experiência. Ao mesmo tempo que, para o Grupo de Usuários, o desconhecimento das funcionalidades, a complexidade do uso e a falta de entendimento do componente como um todo, é o que torna a experiência com o componente desfavorável. Esse aspecto confirma o apontado por Silva (2016) ao afirmar que a leitura obrigatória do manual, com extenso volume de informações, constitui um ponto negativo para o Grupo de Usuários.

\section{e) Mobilidade digitalizada}

Enfim, no que se refere à mobilidade digitalizada, verificou-se que se trata de um conceito polissêmico e que se encontra em um momento de expansão. $\mathrm{O}$ desenvolvimento de uma mobilidade mais digitalizada representa um ponto favorável tanto para o Grupo de Profissionais, quanto para o Grupo de Usuários. Para o Grupo de Profissionais, destaca-se que o fator positivo se encontra associado ao fato da mobilidade digitalizada permitir mais acessibilidade a diferentes modais, como também a possibilidade de se desenvolver soluções personalizadas para os usuários. No que refere ao Grupo de Usuários, a falta de conhecimento relacionada às funcionalidades, a complexidade de uso juntamente com a falta de entendimento do componente como um todo, constitui um limitador no que refere a experiência e se torna um aspecto desfavorável. Patel e Hodgson (2019) também destacam tal aspecto ao distinguir que a digitalização do automóvel, como um serviço pleno, se faz necessário para torná-lo acessível.

No entanto, para que essa mobilidade digitalizada se solidifique, será necessário romper com o arquétipo centenário da indústria automotiva, conforme indicado por Patel e Hodgson (2019). Deve-se focar na busca pelo entendimento do usuário em geral, tornando-o centro do projeto automotivo, e cocriando com este usuário. Tal fato sugere que os veículos tornar-se-ão mais viscerais, comportamentais e reflexivos ao mesmo tempo, conforme a tendência apontada por Norman (2010).

Nota-se que a indústria automotiva ainda precisa investir na experiência do usuário, que será o fator decisivo na evolução do automóvel. Isso significa que a transição para uma nova mobilidade será gradual, com participação efetiva do usuário no processo de desenvolvimento dos sistemas multimeios.

Por fim, em virtude dos fatos discutidos, é provável que o automóvel mantenha o seu status como um produto emblemático e ainda necessário à humanidade. Porém, ele não apresentará a configuração atual: volante, pedais, painel frontal e bancos. Novas tecnologias estarão acessíveis, como os carros autônomos, contudo não se pode dizer que os veículos serão mais eficientes, conectados e intuitivos. E por se tratar de uma relação intangível, uma das principais premissas dos novos projetos automotivos refere-se à forma de como o usuário se relaciona com o software do sistema multimeios.

No Quadro 2 são apresentados os pontos favoráveis e os pontos desfavoráveis a partir dos Grupos de entrevistados. 


\begin{tabular}{|c|c|c|c|}
\hline Grupos & Conceito avaliado & Pontos favoráveis & Pontos desfavoráveis \\
\hline \multirow{5}{*}{ 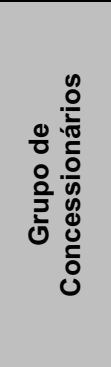 } & A. conectividade & Pareamento smartphone - espelhamento & $\begin{array}{l}\text { Atualizações constantes, feitas na } \\
\text { concessionária }\end{array}$ \\
\hline & B. sistema multimeios & Diferencial de vendas. Muito requisitado & $\begin{array}{l}\text { Alto custo, concorrência com produtos } \\
\text { similares ou melhores }\end{array}$ \\
\hline & $\begin{array}{l}\text { C. parcerias com } \\
\text { empresas de tecnologia }\end{array}$ & $\begin{array}{l}\text { Aceitabilidade diversos sistemas de } \\
\text { operacionais automotivos de } \\
\text { conectividade }\end{array}$ & Alto custo \\
\hline & $\begin{array}{l}\text { D. experiência do usuário } \\
\text { automotivo }\end{array}$ & $\begin{array}{l}\text { Custo-benefício, conforto, atender as } \\
\text { expectativas, entregar um carro completo }\end{array}$ & $\begin{array}{l}\text { Estar defasado perante o concorrente por } \\
\text { não ter um sistema multimeios atual }\end{array}$ \\
\hline & E. mobilidade digitalizada & $\begin{array}{l}\text { Acesso aos sistemas de conectividade, } \\
\text { usuários de aplicativos }\end{array}$ & Alto custo \\
\hline \multirow{5}{*}{$\begin{array}{l}\frac{0}{\pi} \\
\frac{0}{2} \\
\frac{0}{0} \\
\frac{0}{5} \\
\frac{0}{0} \\
\frac{0}{0} \\
\frac{0}{0} \\
\circ \\
\frac{0}{2} \\
\frac{1}{0}\end{array}$} & A. conectividade & $\begin{array}{l}\text { Viabilizadora de mudanças no produto } \\
\text { carro }\end{array}$ & Imaturidade consumidor brasileiro \\
\hline & B. sistema multimeios & $\begin{array}{l}\text { Pórtico de conectividade, elemento de } \\
\text { transformação do mecânico para o digital }\end{array}$ & $\begin{array}{l}\text { Pouco explorado pelo usuário. } \\
\text { Complexidade de projeto, Hardware e } \\
\text { Software }\end{array}$ \\
\hline & $\begin{array}{l}\text { C. parcerias com } \\
\text { empresas de tecnologia }\end{array}$ & $\begin{array}{l}\text { Tendência benéfica, Adição de conteúdo e } \\
\text { facilidades. Aproximação com o } \\
\text { smartphone }\end{array}$ & Burocracia das legislações vigentes \\
\hline & $\begin{array}{l}\text { D. experiência do usuário } \\
\text { automotivo }\end{array}$ & $\begin{array}{l}\text { Novo cenário, traz diversas possibilidades } \\
\text { para melhorar a jornada do usuário }\end{array}$ & $\begin{array}{l}\text { Falta de conhecimento sobre tecnologias } \\
\text { por parte do usuário, mercado limitado por } \\
\text { baixo custo e legislação burocrática }\end{array}$ \\
\hline & E. mobilidade digitalizada & Acessibilidade, Soluções personalizadas & $\begin{array}{l}\text { Romper com a estrutura vigente, } \\
\text { centenária da indústria }\end{array}$ \\
\hline \multirow{5}{*}{ 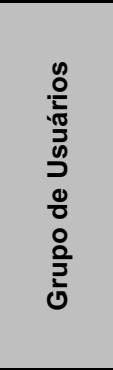 } & A. conectividade & $\begin{array}{l}\text { Interface digital através de uma tela. } \\
\text { Acesso à internet }\end{array}$ & Falta de entendimento \\
\hline & B. sistema multimeios & Status, Hardware de entretenimento & $\begin{array}{l}\text { Complexidade de uso. Ter que ler manual } \\
\text { de instruções }\end{array}$ \\
\hline & $\begin{array}{l}\text { C. parcerias com } \\
\text { empresas de tecnologia }\end{array}$ & $\begin{array}{l}\text { Aproximação com o smartphone. Adição } \\
\text { de tecnologias e facilidades }\end{array}$ & $\begin{array}{l}\text { Invasão de privacidade. Desconhecem } \\
\text { como seus dados pessoais seriam usados }\end{array}$ \\
\hline & $\begin{array}{l}\text { D. experiência do usuário } \\
\text { automotivo }\end{array}$ & $\begin{array}{l}\text { Mais possibilidades de uso, } \\
\text { aproveitamento do tempo, através das } \\
\text { possibilidades de acesso à internet }\end{array}$ & $\begin{array}{l}\text { Desconhecimento das funcionalidades dos } \\
\text { multimeios, falta de usabilidade - } \\
\text { complicado usar e entender o todo }\end{array}$ \\
\hline & E. mobilidade digitalizada & $\begin{array}{l}\text { Tecnologia, carros autônomos, Acesso a } \\
\text { serviços diversos }\end{array}$ & Perder o controle do veículo, insegurança \\
\hline
\end{tabular}

Quadro 2: Pontos favoráveis e desfavoráveis listados a partir das entrevistas dos respectivos Grupos de entrevistados. Fonte: Ribeiro (2020, p.86).

Portanto, o sistema multimeios do automóvel dentro do conceito da mobilidade digitalizada representará uma união indissociável entre hardware e software, ou seja, a integração entre esses dois entes de maneira equilibrada, harmônica e que permitirá mais satisfação na experiência vivenciada pelo usuário no interior do veículo.

\section{Conclusão}

A automatização veicular se tornará responsável pela forma como as pessoas interagirão com os veículos e o sistema multimeios se tornará uma espécie de portal para esse novo universo. As novas exigências no desenvolvimento dos carros e da nova mobilidade têm se tornado um fato-chave nos novos projetos e que se mostra como variável de impacto crescente no mercado mundial. Além disso, tem-se que o ato de dirigir hoje não terá o mesmo enfoque no amanhã. O sistema multimeios constitui o componente focal para essa mudança, passando de um simples aparelho centralizado no carro, quanto à configuração física, para a integralização e indissociabilidade do veículo em si.

Conforme verificado nas entrevistas com o Grupo de Usuários e o Grupo de Profissionais, atributos físicos como formas, acabamento, tamanho da tela e posição no veículo ainda são significativamente valorizados, ou entendidos como símbolo de conectividade dentro de um veículo, ao invés da real interação de uso. Apesar da oposição de opiniões e pontos de vista entre os três Grupos de entrevistados e o impacto na interação com sistemas multimeios de veículos, foi possível identificar quatro aspectos: 
I - a conectividade, através do sistema multimeios, está cada vez mais em destaque e em uso nos automóveis;

II - o sistema multimeios tem se tornado o elemento transacional do carro produto para o carro serviço na mobilidade do futuro;

III - é prerrogativa que a indústria automotiva se associe ou incorpore as expertises das empresas de tecnologias da comunicação;

IV - a aplicação dos conceitos relacionados à experiência do usuário se mostra como poderosa ferramenta para reduzir as frustrações dos usuários quanto à utilização dos novos automóveis, em função do crescente aporte do sistema multimeios em seus interiores.

Assim como no smarthphone, entender como as pessoas fazem chamadas de áudio/vídeo hoje dentro dos seus veículos, como utilizam o comando de voz, quantos toques e quanto tempo desprendem para conseguir realizar determinada tarefa, dentre outras ações e tarefas, são requisitos fundamentais para entender a jornada e mapear a experiência do usuário junto aos veículos. O carro está trilhando o mesmo caminho dos antigos aparelhos celulares, pois, está ganhando em extensão de utilização e se desprendendo da função primária do arquétipo original. O carro está incorporando meios e tecnologias para re-significá-lo como smartcar.

\section{Referências Bibliográficas}

ABEMD - ASSOCIAÇÃO BRASILEIRA DE MARKETING DE DADOS. Os consumidores gostam de tecnologia no carro. 2019. Disponível em: https://abemd.org.br/noticias/os-consumidores-gostam-detecnologia-no-carro. Acesso em: 21 nov. 2019.

AGNER, Luiz. Ergodesign e arquitetura de informação: trabalhando com o usuário. $4^{\mathrm{a}}$ ed., Rio de Janeiro: Senac Rio, 2018.

AUTOESPORTE. Como escolher uma boa central multimídia? São Paulo, 05 de fevereiro de 2018. Disponível em: https://revistaautoesporte.globo.com/Noticias/noticia/2018/02/como-escolher-uma-boacentral-multimidia.html\#. Acesso em: 28 ago. 2019.

BHISE, Vivek D. Ergonomics in the automotive design process. Boca Raton-FL: Taylor \& Francis Group, 2012.

CHOMETON, Alain. Architecture automobile: tendances, évolutions, securité, design, ergonomie, confort, performances, hybridation. Paris: Ellipses Édition Marketing, 2011.

CONSELHO NACIONAL DE TRÂNSITO - CONTRAN. Resolução CONTRAN nº 242/2007. Equipamentos geradores de imagens. 2007.

COZER, Carolina. O que muda no consumo de automóveis depois da pandemia? Consumidor moderno, 26 de maio de 2020. Disponível em: https:/www.consumidormoderno.com.br/2020/05/26/consumoautomoveis-depois-pandemia/. Acesso em: 26 maio 2020.

CHANDRA, Ronal; AGANI, Nazori; PRIHASTOMO, Yoga. Self-driving car: Artificial intelligence approach. Tese (Master of Computer Science), University of Budi Luhur Jl. Raya Ciledug, Jakarta 12260 Indonesia 2012. Journal TICOM, v.1, n. 1, setembro 2012. Disponível em: 
https://media.neliti.com/media/publications/93435-EN-self-driving-car-artificial-intelligence.pdf. Acesso em: 23 maio 2019.

EUROPEAN DATA PROTECTION BOARD. Guidelines 1/2020 on processing personal data in the context of connected vehicles and mobility related applications. Version 1.0. 2020. Disponível em: https://edpb.europa.eu/sites/default/files/consultation/edpb_guidelines_202001_connectedvehicles.pdf. Acesso em: 11 de dez de 2021

FONTANA, Guilherme. Quatro Rodas: o valor das centrais multimídia no mercado de novos e usados. 2016. Disponível em: https://quatrorodas.abril.com.br/noticias/o-valor-das-centrais-multimidia-no-mercadode-novos-e-usados/. Acesso em: 28 ago. 2019.

GERHARDT, Tatiana Engel; SILVEIRA, Denise Tolfo (org.). Métodos de pesquisa. $1^{\text {a }}$ ed., Porto Alegre: UFRGS, 2009.

GIL, Antônio C. Como elaborar projetos de pesquisa. 4a ed., São Paulo: Atlas, 2007.

IIDA, Itiro. Ergonomia: projeto e produção. $2^{\text {a }}$ ed., São Paulo: Edgard Blücher, 2005.

INTERACTION DESIGN FOUNDATION. What is UX Research? 2019. Disponível em: https://www.interaction-design.org/literature/topics/ux-research. Acesso em: 22 nov. 2019

ISO. INTERNATIONAL ORGANIZATION FOR STANDARDIZATION. Norma ISO: 9241-11: 2010 Ergonomia da interação sistema humano, International Organization for Standarlization, parte 210, 2010. Disponível em: https://www.iso.org/obp/ui/\#iso:std:iso:9241:-210:ed-1:v1:en. Acesso em: 30 jul. 2018.

KALBACH, Jim. Mapeamento de experiências: um guia para criar valor por meio de jornadas, blueprints e diagramas. Tradução Eveline Machado. $1^{\mathrm{a}}$ ed., Rio de Janeiro: Alta Books, 2017.

LGPD. Lei Geral De Proteção De Dados. Lei No 13.709, de 14 de agosto de 2018. Presidência da República. Disponível em: http://www.planalto.gov.br/ccivil_03/_ato20152018/2018/lei/L13709compilado.htm. Acesso em: 11 dez. 2021.

LIRA, Vinicio. O que é central multimídia: lazer, informação e conforto dentro do seu carro. 2019. Para Promobit. Disponível em: https://www.promobit.com.br/blog/o-que-e-central-multimidia-lazer-informacaoe-conforto-dentro-do-seucarro/\#: :text=Uma\%20central\%20multim\%C3\%ADdia\%2C\%20ou\%20Kit,m\%C3\%ADdia $\% 20 \mathrm{em} \% 20 \mathrm{um}$ \%20\%C3\%BAnico\%20aparelho. Acesso em: 12 nov. 2019.

LÖBACH, Bernd. Design industrial: bases para a configuração dos produtos industriais. $1^{\mathrm{a}}$ ed., São Paulo: Editora Edgard Blücher, 2001.

LOWDERMILK, Travis. Design centrado no usuário: um guia para o desenvolvimento de aplicativos amigáveis. Tradução Lúcia Ayako Kinoshita. 1ª ed., São Paulo: Novatec O’Reilly Media, 2013.

MARCONI, Mariana de A.; LAKATOS, Eva Maria. Técnicas de pesquisa: planejamento e execução de pesquisas, amostragem e técnicas de pesquisa, elaboração, análise e interpretação de dados. $7^{\mathrm{a}}$ ed., São Paulo: Atlas, 2012.

MATSUBARA, Vitor. Tudo a bordo. Revista Quatro Rodas, digital, 2 de mar. 2016. Disponível em: https://quatrorodas.abril.com.br/noticias/tudo-a-bordo/. Acesso em: 23 mar. 2021. 
MEDEIROS, Cindy Renate Piassetta X. Avaliação do cockpit de veículos automotores do transporte de carga: método apoiado na ergonomia e na usabilidade. Dissertação (Mestrado em Engenharia Mecânica) Universidade Federal do Paraná. Curitiba, 2004. 256 p.

MICHELLI, Joseph A. Guiados pelo encantamento: o método Mercedez-Benz para entregar a melhor experiência do cliente. São Paulo: DVS, 2017.

MILLER, Randall J.; SIMLETT, John; SCHONDORF, Kristin M.; LONGO, Mike; VALSAN, Anil; GRANT, Regan. Remodeling for mobility: will new mobility mean the end of "old" automotive? Eygm Limited. Ernst \& Young Global Limited. 2016. 12p. Disponível em:

http://www.automotivebusiness.com.br/abinteligencia/pdf/Remodeling\%20for\%20mobility\%20FINAL\%20( 1).pdf. Acesso em: 10 jul. 2018.

NORMAN, Donald A. O design do futuro. Rio de Janeiro: Rocco, 2010.

PATEL, Shiv; HODGSON, James. Next generation automotive infotaiment. ABI Research. 2019.

RIBEIRO, Talita Muniz. As implicações do design de experiência nos sistemas multimeios na construção da nova mobilidade. Dissertação (Mestrado em Design), Programa de Pós-Graduação em Design, Universidade do Estado de Minas Gerais, Belo Horizonte. 2020. 96p.

SAFFER, Dan. Designing for interaction: Creating innovative applications and devices. $2^{\mathrm{a}}$ ed., Berkeley: New Riders, 2010.

SILVA, Maria Luíza Viegas R. O uso intuitivo nos automóveis populares: uma abordagem cognitiva voltada para idosos. Dissertação (Mestrado em Design), Programa de Pós-Graduação em Design, Universidade do Estado de Minas Gerais, Belo Horizonte. 2016. 136 p. Disponível em: https://docplayer.com.br/47249975-O-uso-intuitivo-nos-automoveis-populares-uma-abordagem-cognitivavoltada-para-idosos.html. Acesso em: 18 ago. 2018.

SUDJIC, Deyan. A linguagem das coisas. 1ª ed., Rio de Janeiro: Intrínseca, 2010.

UNGER, Russ; CHANDLER, Carolyn. A project guide to ux design: for user experience designers in the field or in the making. Berkeley: New Riders, 2009. 